\title{
A eleição de Iván Duque na Colômbia e o processo de paz com as FARC-EP: continuidade ou ruptura?
}

The election of Ivan Duque in Colombia and the peace process with FARC-EP: continuity or rupture?

Matheus de Abreu Costa Souza ${ }^{1}$

Pedro Diniz Rocha ${ }^{2}$

\section{RESUMO}

O objetivo deste artigo é explorar quais são as possibilidades para o andamento do processo de paz entre a Colômbia e as FARC-EP após o início do mandato do presidente Iván Duque em agosto de 2018. Acredita-se que as mudanças propostas pelo novo presidente podem comprometer o processo de paz na medida em que perfazem pontos fundamentais no cálculo estratégico do grupo armado na decisão de renunciar ao conflito armado.

Palavras-chave: Colômbia; FARC-EP; FARC; Iván Duque.

\begin{abstract}
The aim of this article is to explore the possibilities for the continuation of the peace process between Colombia and FARC-EP after the beginning of Iván Duque's mandate in August 2018. It is believed that the fundamental changes proposed by the new president can endanger the peace process as they target elements of the strategic calculation of the armed group in its decision to withdraw from the armed conflict.
\end{abstract}

Keywords: Colombia; FARC-EP; FARC; Iván Duque.

1. Mestrando em Relações Internacionais pela Pontifícia Universidade Católica de Minas Gerais, Belo Horizonte, Brasil. ORCID-ID: 0000-0002-0734-475X.

2. Mestrando em Relações Internacionais pela Pontifícia Universidade Católica de Minas Gerais, Belo Horizonte, Brasil. ORCID-ID: 0000-0002-1365-3292 


\section{Introdução}

Iván Duque, candidato pelo partido Centro Democrático $(\mathrm{CD})$, elegeu-se presidente da Colômbia, em 17 de junho de 2018, após derrotar nas urnas Gustavo Pedro (Movimiento Progresistas) com 54\% dos votos válidos. A oposição a Juan Manuel Santos e às negociações de la Habana são eixos fundacionais do partido de Duque, que, embora descarte, em termos de Fernando Lodońo (ex-Diretor Nacional do $\mathrm{CD}$ ), levar o acordo às ruínas, defende a realização de mudanças substanciais no acordo de paz assinado em dezembro de 2016 com as Forças Armadas Revolucionárias da Colômbia Exército do Povo (FARC-EP) (FERNANDO LODOÑO HAY..., 2017). Em direção a uma "paz sem impunidade", os discursos de Duque e do CD questionam, sobretudo, o modelo de justiça transicional adotado no acordo e a participação das lideranças das FARC-EP na esfera política colombiana (MANDETTO, 2018).

Dito isto, o eixo delineador deste artigo conjuntural é explorar quais são as possibilidades futuras para o andamento do processo de paz entre a Colômbia e as FARC-EP após a eleição de Duque. Acredita-se que as mudanças propostas pelo CD podem comprometê-lo na medida em que perfazem dois pontos fundamentais no cálculo estratégico das FARC-EP: i) a adoção de modelo de justiça restaurativa em contraposição à justiça punitiva-retributiva, o que garante penas alternativas e anistia a crimes políticos conexos ao conflito; ii) a participação política do grupo, o que assegura a possibilidade da busca de seus objetivos por via democrática e não pelo uso da força.

Com o objetivo de explorar a temática, o presente artigo segue subdividido em três seçóes, para além desta introdução e das consideraçóes finais. $\mathrm{Na}$ primeira seção será apresentado um breve panorama do conflito entre a Colômbia e as FARC-
-EP, de modo a apontar os principais desafios para a implementação da paz no país. Na segunda seção serão identificados os principais pontos do acordo de 2016 e de que maneira se combate as causas intrínsecas ao conflito. Por fim, na terceira seção, será analisada a posiçáo do partido Centro Democrático, em geral, e de Iván Duque, em particular, acerca do acordo de la Habana e as possibilidades e consequências da transformação de seus termos para o andamento do processo de paz na Colômbia.

\section{Origens e análise do conflito entre Colômbia e FARC-EP}

A origem do conflito entre a Colômbia e as Forças Armadas Revolucionárias da Colômbia Exército do Povo (FARC-EP), que emergiu em 1964, pode ser relacionado à conjuntura colombiana nas décadas anteriores. Com o estabelecimento do pacto Frente Nacional, que deu fim a um período muito conturbado na história colombiana, denominado como La Violencia (1948-1958)³, partidos políticos de menor expressão foram excluídos pelo pacto de poder concorrer nas quatro futuras eleições presidenciais. É neste contexto que se iniciou, na década de 1960, sob influência do Partido Comunista, a mobilização de grupos armados, compostos por militantes campesinos, contra a coligação Frente Nacional e com o objetivo de promover uma reforma agrária na Colômbia, dentre eles as FARC-EP (GALLEGO, 2010).

Assim como os movimentos guerrilheiros influenciados pelo Partido Comunista, o objetivo geral das FARC-EP era a tomada do governo, para

3. Período histórico caracterizado por tentativas violentas de "homogeneização política" do país, por meio de grupos armados que se denominavam conservadores ou liberais (GALLEGO, 2010; AZCARATE, 1999). O período "La Violencia" foi dado como terminado com a assinatura, em 1958, de um pacto, denominado como Frente Nacional, entre o Partido Liberal e o Partido Conservador, que previa um regime de coalizão entre as partes, com alternância destes partidos no poder nos dezesseis anos seguintes (VILLEGAS, 2017) 
que o grupo rompesse com a Frente Nacional e pudesse emplacar sua agenda em favor aos desfavorecidos socioeconomicamente, em defesa de uma reforma agrária democrática, que cedesse as terras férteis aos produtores campesinos pobres, e contra a privatização dessas terras e de recursos naturais disponíveis em território colombiano. Para atingir esse objetivo, as FARC-EP possuíram uma característica de luta armada, aspecto que, ao passo que fortaleceu o grupo em seus anos iniciais, enfraqueceu futuramente o grupo, na medida em que se tornou foco de um discurso do governo colombiano que criminalizou as atividades do grupo ${ }^{4}$ (FELTER; RENWICK, 2017; GALLEGO, 2010).

Tendo em vista esta consideração inicial acerca dos objetivos das FARC-EP, é possível identificar uma situação de conflito, na medida em que conflitos são entendidos, de acordo com Peter Wallensteen (2007, p. 15), como “(...) uma situação social na qual um mínimo de dois atores (partes) se esforçam para atingir, em um mesmo momento, um conjunto de recursos escassos". No caso do conflito entre a Colômbia e as FARC-EP, o recurso escasso em disputa é o poder político, tendo em vista que este representa um recurso atrativo, que possibilitaria, para os diferentes grupos, a perseguição de suas distintas agendas. Este conflito também pode ser localizado na tricotomia dos conflitos de Wallensteen (2007) como um conflito intraestatal, na medida em que uma das partes beligerantes é o Estado (e suas forças regulares), enquanto a outra parte é um ator não-estatal (as FARC-EP). Assim, tendo em vista a natureza da reivindicação e a presença de atores não estatais e estatais, é possível inferir que o embate entre Colômbia e FARC-EP é um conflito intraestatal pelo poder.

4. Uma atividade que recebeu muitas críticas dentro da Colômbia foi o uso de crianças como combatentes. Para aprofundar sobre o uso de crianças soldado pelas FARC-EP, consultar Patricia Nabuco Martuscelli \& Rafael Duarte Villa (2018).
Em grande medida, os conflitos intraestatais são associados a questôes étnicas, religiosas e culturais. Entretanto, é interessante notar que no caso do conflito na Colômbia, não é possível inferir que o conflito esteja relacionado a um contorno étnico, religioso ou cultural evidente. A razão do conflito obedece uma lógica que é, em sua essência, política (RESTREPO et al, 2004). Nesse sentido, como argumentado por Wallensteen (2007), o processo de resolução de um conflito intraestatal pelo poder deve, necessariamente, contemplar de forma satisfatória a reivindicação principal do grupo armado, que, no caso do conflito entre a Colômbia e as FARC-EP, era o acesso dos membros do grupo à cargos políticos.

$\mathrm{O}$ acesso dos grupos ao poder está geralmente previsto nos acordos de paz, documentos que, teoricamente, dáo fim à mobilização armada e estabelecem uma agenda com compromissos políticos estabelecidos entre as partes. Os acordos de paz devem ser passíveis de serem incorporados na legislação dos Estados, ou seja, precisam ser legalmente viáveis. Outro aspecto crucial dos acordos de paz é que eles precisam ser extremamente precisos no que tange ao combate às causas dos conflitos, para que este seja, então, considerado como um bom acordo de paz, capaz de evitar o ressurgimento da violência armada. Por fim, os acordos de paz precisam lidar com a reintegraçáo dos ex-combatentes na vida social e as partes devem entrar em um acordo com relação à forma de justiça que será empregada para lidar com os crimes de guerra realizados por ambas as partes durante a disputa violenta (WALLENSTEEN; ERIKSSON, 2009).

Entretanto, implementar os acordos de paz não é uma tarefa simples, tendo em vista que esse processo se dá em ambientes complexos, altamente interdependentes e, em certos contextos, frágeis. De acordo com Jacob Bercovitch e Leah Simpson (2010), existem quatro aspectos que podem faci- 
litar a implementação dos acordos de paz. O primeiro deles é relativo à especificidade do acordo. Argumenta-se que é necessário que os acordos de paz toquem em questóes cruciais de forma específica, na medida em que as partes terão clareza do que deve ser feito após a assinatura do acordo. Este argumento coincide com a ideia de Virginia Fortna (2003), que argumenta que há maior probabilidade de sucesso na implementação dos acordos se as cláusulas dispostas sejam específicas. $\mathrm{O}$ segundo ponto é a existência de mediadores que se coloquem como garantidores do processo de paz, criando condições para a implementação dos tópicos previstos. Em terceiro lugar, os autores reconhecem que deve se levar em consideração a complexidade do ambiente em que o acordo será implementado, observando, principalmente, a presença de spoilers ${ }^{5}$ no ambiente. Por fim, Bercovitch e Simpson (2010) colocam que o sucesso na implementação do acordo está relacionado à capacidade das partes em estabelecer arranjos de compartilhamento de poder, para garantir a inserção dos beligerantes à esfera política.

No caso colombiano, os principais desafios relacionados às negociações e à implementação do acordo de paz com as FARC-EP, estiveram historicamente relacionados sobretudo ao último ponto citado, relativo à inserçáo política do grupo, e, também, em relação à provisão da justiça. Essa dificuldade está intimamente relacionada ao grande número de atividades ilícitas que o grupo se envolveu desde sua criaçáo com o objetivo de financiar sua luta armada. Dentre as atividades ilícitas, a que ganha maior destaque é a associação do grupo às atividades de narcotráfico. Assim, ao longo dos anos, a criminalizaçáo das FARC-EP provocou uma aversão da sociedade para com o grupo, ten-

5. De maneira geral, os spoilers são atores que visam promover a falha do acordo de paz, na medida em que são contrários à implementação dos termos do acordo em questão. Essas partes podem ser lideranças e facções. Para maiores informações teórico-conceituais sobre os spoilers, consultar Stephen Stedman (1997). do em vista que a falta de segurança e problemas socioeconômicos na Colômbia passaram a ser comumente associados às atividades ilícitas que eram realizadas. Esta intensa criminalização do grupo é, então, um aspecto que dificultou a criação de um acordo que fosse capaz de promover a reintegraçáo dos ex-combatentes na sociedade, bem como a aceitação popular no que tange a inserção dos líderes das FARC na política nacional (ZARAMA, 2016; GALLEGO, 2010). Tendo estes principais desafios em vista, a próxima seção tem como objetivo discutir como o acordo de paz assinado entre o governo da Colômbia e as FARC em 2016, promoveu um combate às causas do conflito e lidou com os desafios supracitados.

\section{O acordo de paz de la Habana (2016)}

Após anos de criminalização, negociações malsucedidas e um intenso combate militar das FARC-EP, a gestão do presidente Juan Manuel Santos (iniciada em agosto de 2010) colocou como prioridade a negociaçáo entre o governo colombiano e as FARC-EP. As negociaçóes formais entre as partes se iniciaram em 2012 e, durante o processo, houve uma significativa redução das hostilidades entre as partes, ao passo que as incompatibilidades, separadas em tópicos, foram negociadas gradativamente. Dentre os tópicos negociados, destaca-se a questão do narcotráfico, os termos da reforma agrária, a participação política dos ex-combatentes, sua reintegração na sociedade e as formas de reparação e justiça para com as vítimas do conflito (COLÔMBIA, 2016; CRONOLOGÍA DE LAS..., 2015).

Após as diversas rodadas de negociação, um acordo de paz final, que reuniu todas as decisóes discutidas separadamente, foi assinado entre a Colômbia e os representantes das FARC-EP em 24 de novembro de 2016 (COLÔMBIA, 2016). 
Em relaçáo ao conteúdo do acordo, fazendo um paralelo com os pontos que levantados em Bercovitch e Simpson (2010), o acordo de paz assinado entre as partes é bastante completo e específico, delimita com precisão os prazos, processos e lista de prioridades para a implementação das cláusulas. Embora as negociaçóes tenham sido feitas bilateralmente, diversos grupos internacionais estáo atuando como observadores no processo de transição para a paz. Como se trata de um processo recente, ainda não foi possível identificar a existência de partes recalcitrantes (spoilers). Por fim, o acordo prevê a inserção política dos ex-combatentes, demanda central das FARC-EP (COLÔMBIA, 2016). Discutiremos, adiante, as principais questôes previstas no acordo de paz.

Após ratificação no congresso, os termos do acordo entraram em vigor no dia 01 de dezembro do mesmo ano, sendo a desmobilização armada das FARC-EP a primeira medida a ser implementada. Aos auspícios da Missão de Verificação da ONU na Colômbia, composta por um grupo de observadores desarmados, o processo de remoção dos armamentos do grupo foi finalizado em 15 de agosto de 2017 (OBSERVADORES DA ONU..., 2017; COLÔMBIA, 2016).

Outro ponto acordado entre as FARC e o governo colombiano é a realizaçáo de uma reforma agrária integral, que possui dois eixos orientadores: a distribuição entre os produtores e população campesina de terras estatais ou terras adquiridas de forma ilegal ao longo do conflito e a implementaçáo de programas que promovam o desenvolvimento socioeconômico nas áreas rurais. $\mathrm{O}$ acordo visa contemplar estes dois pontos por meio da regularizaçâo de terras já ocupadas por produtores rurais, concessão de créditos para que a população campesina seja capaz de regularizar suas propriedades, além das políticas de redistribuição a serem implementadas. Ademais, acordou-se que políticas voltadas para o desenvolvimento de infraestrutura, educação, saúde, assistência técnica, dentre outros programas que deveriam ser direcionados às zonas rurais (COLÔMBIA, 2016; MELO, 2016).

O acordo também prevê a mobilização dos membros do grupo em um partido político após a entrega dos armamentos e muniçóes. Assim, em setembro de 2017, o grupo renomeou a sua sigla e se estabeleceu como um partido político, denominado como Força Alternativa Revolucionária do Comum (FARC). De acordo com os termos do acordo, independentemente dos resultados das eleições entre os anos de 2018 e 2026, as FARC teriam um mínimo de cinco assentos cativos no senado, e outros cinco na câmara dos deputados. Essa medida seria responsável por garantir a representatividade política das FARC em um período inicial, reivindicação central do grupo, tendo em vista que a falta de popularidade do grupo perante a sociedade colombiana é um impedimento para que estes representantes sejam eleitos por meio de votos diretos (COLÔMBIA, 2016; COLOMBO, 2017)

O acordo de paz também toca na questáo da justiça e dos mecanismos de reparação a serem implementados para este fim, algo crucial para a reconciliação nacional em momentos pós-conflito. Assim, o acordo prevê a criação de uma comissão denominada como Justiça Especial para a Paz (JEP), que é dividida entre a Comissão da Verdade, uma comissão para localizaçáo de desaparecidos no conflito e, por fim, uma comissão de jurisdição da paz. A Comissão da Verdade seria responsável por prover informaçôes que esclareçam os crimes empregados pelas FARC-EP nos anos de conflito armado. Suas atividades estáo intimamente relacionadas ao comitê de localização, auxiliando as famílias das vítimas a obter informaçôes sobre os familiares desaparecidos. A função dessas duas primeiras comissóes é apenas informativa, e não tem como objetivo sancionar os responsáveis por tais crimes. Os julgamentos e san- 
çóes serão feitos por uma comissão especial, a JEP, que é uma forma alternativa de julgamento, que concede anistia aos responsáveis por crimes políticos (e conexos). Entretanto, puniçóes serão aplicadas aos responsáveis por crimes contra a humanidade e de guerra, podendo estas variarem entre breves penas restritivas de liberdade à penas restritivas de direitos, tais como: realização de trabalhos voluntários temporários - como, por exemplo, em obras para reestruturação da infraestrutura da Colômbia (COLÔMBIA, 2016; MELO, 2016). É possível inferir, então, que a justiça transicional adotada não será promovida por meio de longas puniçóes e restriçóes da liberdade, aspecto central para as lideranças das FARC-EP durante as negociações.

Por fim, como mencionado na seção anterior, o narcotráfico ocupou papel relevante para o financiamento da luta armada das FARC-EP, e este fluxo ilegal de drogas se intensificou ao longo dos anos do conflito, e, atualmente, é um dos grandes problemas da sociedade colombiana. Assim, no tocante da questáo do narcotráfico, espera-se dos ex-combatentes uma ativa colaboração e compromisso para com o combate desta prática. Não está previsto no acordo de paz o julgamento e a punição dos ex-combatentes pela produçáo e comercialização das drogas ilícitas durante os anos do conflito, tendo em vista que as atividades de narcotráfico estavam conexas ao crime de rebeliáo, que isentava a punição dos envolvidos (COLÔMBIA, 2016). Entretanto, veremos na próxima seção que há uma grande pressão do presidente eleito, Iván Duque, para modificação desse componente do acordo.

Por meio de um cuidadoso monitoramento, o Instituto Kroc de Estudos para a Paz, da Universidade de Notre Dame, analisou qualitativamente e quantitativamente o processo de implementação do acordo de paz na Colômbia, por meio de um relatório de acompanhamento lançado em 09 de agosto de 2018. Tal relatório divide o acordo entre
578 tópicos a serem cumpridos pelas partes, e os dados mostram que, até maio de 2018, 61\% dessas implementaçôes já foram iniciadas - sendo que $21 \%$ foram totalmente cumpridas, $9 \%$ foram cumpridas de forma intermediária, enquanto $31 \%$ dos pontos do acordo foram implementados de forma mínima/inicial. Nota-se, então, que vários pontos do acordo já foram ou estão sendo contemplados e incorporados pelas partes, o que pode fortalecer o comprometimento mútuo para com o acordo de paz (KROC INSTITUTE, 2018).

Embora a implementação do acordo tenha tido um pequeno avanço em relação ao ano de 2017, ainda é possível observar que pontos cruciais do acordo ainda não foram implementados de forma abrangente (KROC INSTITUTE, 2018). Esta informação fica evidente no Gráfico 1 abaixo, que separa as 578 provisóes em 6 principais tópicos.

Analisando o gráfico, é possível observar que as questóes relativas à reforma agrária, principal objetivo das FARC-EP em sua emergência, tem avançado lentamente - apenas $2 \%$ das provisóes foram totalmente implementadas, 3\% foram implementadas de forma intermediária, e $45 \%$ das medidas estão em processo de implementação, ao passo que $50 \%$ ainda não foram iniciadas. O relatório aponta que as dificuldades de implementar as medidas cruciais relativas à reforma agrária estão relacionadas ao atraso e fragmentação do poder legislativo em relação às medidas a serem empregadas para atender a reforma agrária prevista no acordo de paz. Além disso, outro aspecto que tem impedido o avanço nessa esfera é a desarticulação entre as medidas previstas no acordo de paz, o Programa Nacional Integral para Substituição de Cultivos Ilícitos (PNIS) e o Plano de Desenvolvimento com Enfoque Territorial (PDET). Essa desarticulação, ainda de acordo com o relatório, provoca falta de clareza acerca das medidas a serem aprovadas e implementadas (KROC INSTITUTE, 2018). 
Grófico 1 - Visão geral da implementação do acordo final por ớreas temáticars

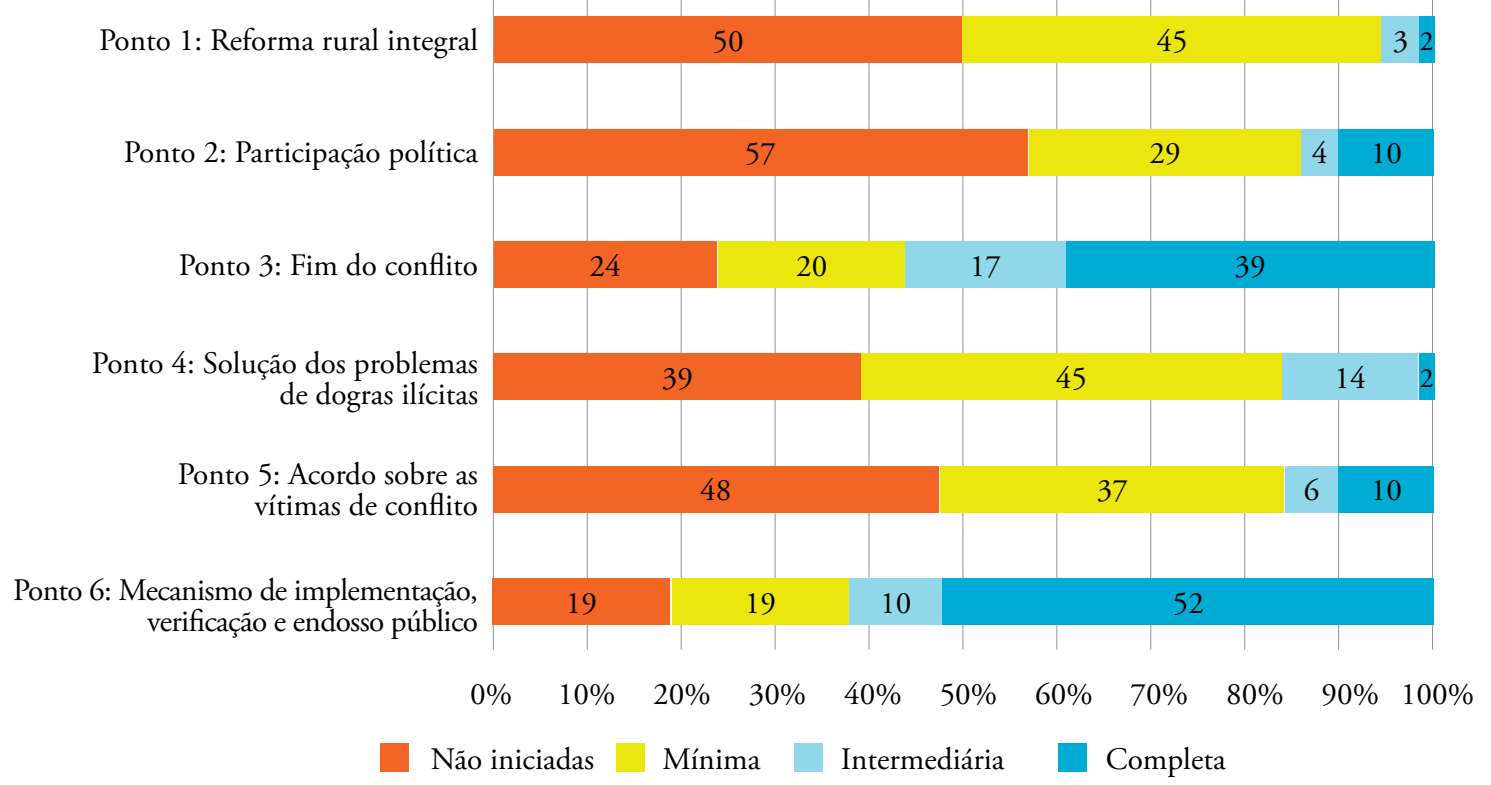

Fonte: Adaptado de Kroc Institute, 2018, p. 23.

Ainda de acordo com o gráfico, percebe-se também a lentidão em promover a reforma política que garantiria a participaçáo política de ex-combatentes do grupo armado e de populaçóes campesinas. Este ponto é visto com preocupação no relatório, na medida em que diversas travas foram identificadas, dificultando a implementação de medidas vistas como cruciais no acordo de 2016 (COLÔMBIA, 2016; KROC INSTITUE, 2018). Poucas mudanças normativas foram feitas até o momento, tendo em vista que cláusulas e recomendaçōes previstas no acordo estão encontrando barreiras para aprovação a nível nacional. Os atrasos têm sido, sobretudo, em aderir as propostas relativas à reforma política e eleitoral, garantia e promoção da participação política da sociedade, dentre outros (KROC INSTITUTE, 2018). Esse ponto é especialmente preocupante pois, como visto em Wallensteen (2007), garantir a representatividade política dos grupos que antes reivindicavam pelo poder estatal é crucial para que o processo de resolução do conflito obtenha sucesso. Para além dos desafios nessas duas questões principais, a eleição de Iván Duque também tem levantado incertezas acerca da continuidade do processo de paz, questáo que será discutida adiante.

\section{A eleição de Ivón Duque: críticas ao acordo e possibilidades de modificação}

Desde o início das negociaçóes de la Habana, a oposição ao acordo de paz e a Juan Manuel Santos tem sido as bandeiras políticas tanto do ex-presidente Álvaro Uribe, em particular, como do partido Centro Democrático, no geral (GÓMEZ, 2017). Em certo sentido a própria fundação do partido pelos partidários do ex-presidente em 2013 se deu em contrariedade à "paz de Juan Manuel Santos". Isto é, a identidade política do CD é fundamentada a partir de uma relaçâo entre o "eu" e "outro". Este ponto pode ser percebido na medida em que a segurança democrática é um dos cinco pilares fundamentais do partido (LOSADA; LIENDO, 2016). 
A partir da Politica de Seguridad Democrática (PSD), Álvaro Uribe durante seus dois mandatos (2002-2010) adotou política de governo voltada ao combate militar dos grupos insurgentes, sendo o diálogo com as FARC-EP curso de ação improvável em contexto em que nem mesmo seu status de grupo político era reconhecido. A paz no uribismo, portanto, "não nasce da negociação, mas da imposição da autoridade estatal" sobre os grupos insurgentes (ATEHORTÚA, 2016, p. 21). Nesta chave se compreende a posição do partido $\mathrm{CD}$ de que o diálogo com as FARC-EP não é o curso de ação mais apropriado, na medida em que o grupo guerrilheiro estaria em la Habana buscando ganhar tempo e vantagem de modo a se recuperar dos revezes militares impostos durante o governo Uribe (GÓMEZ, 2017). Em termos discursivos, desenha-se a "paz de Santos" como sinônimo de governo débil que póe em risco o Estado ao se mostrar incapaz de combater de maneira efetiva os grupos insurgentes (ATEHORTÚA, 2016).

Ao longo da campanha de Iván Duque à presidência, se não somente contrário aos termos do acordo, membros do CD destacaram ser objetivo levar acordo final com as FARC-EP às ruínas (FERNANDO LODOÑO HAY..., 2017). De qualquer maneira, em discursos recentes Duque moderou o tom oposicionista, declarando ser sua intenção não acabar com o acordo, mas modificar de forma substantiva o texto ratificado pelo congresso (MANDETTO, 2018). Perguntado em entrevista ao El País, em janeiro de 2018, sobre quais seriam as mudanças fundamentais a serem buscadas pelo Centro Democrático se eleito, o então candidato afirmou que,

é muito grave ter-se permitido que as lideranças das FARC sejam candidatos a presidência e ao congresso da república sem ter dito toda a verdade, sem ter reparado as vítimas e sem ter cumprido pena pelos delitos que cometeram... Ademais, os cultivos ilícitos na Colôm- bia vêm aumentando e lograram ao narcotráfico ser um delito anistiável, dizendo que era conexo a delito político. Tenho claro que se chego a presidência vou apresentar reforma constitucional para que se tenha na constituição colombiana que o narcotráfico não é um delito anistiável. s. o. A Justiça Especial para Paz (JEP) tal como está é um mecanismo de impunidade que permite a elegibilidade política de criminosos de lesa humanidade, e ficou claro que, ali, dizer toda a verdade não significa aceitar todas as responsabilidades. Assim, por isso, é uma piada as vítimas e uma afronta a nosso Estado de Direito (DUQUE apud MANDETTO, 2018, s/p).

A partir da fala de Iván Duque, se destacam três tópicos inter-relacionados a se buscar modificação quando do início de seu mandato em agosto de 2018: os termos da JEP, a participação política das FARC e questôes relativas ao narcotráfico. Essas três questôes serão discutidas adiante.

Em primeiro lugar, em relação à JEP, Duque e o partido Centro Democrático entendem que a adoçâo de modelo de justiça restaurativa ${ }^{6}$ e a inclusão de cerca de 1800 oficiais do exército colombiano no processo de jugo leva a cenário onde os verdadeiros culpados alcançam impunidade, enquanto àqueles defensores da soberania da nação são tratados como criminosos. No que concerne a implementação dos termos da JEP, sua instauraçáo foi homologada em 15 de março de 2018, os juízes que compóem a casa já foram selecionados e os primeiros 18 casos já estão em processo de deliberação. De qualquer maneira, até o momento somente $13 \%$ dos 38 termos estipulados acerca desta questão no acordo de paz foi, de fato, implementado (INTERNATIONAL CRISIS GROUP, 2018; KROC INSTITUTE, 2018, p.54). Em segundo lugar, em relação a participação política das FARC nos termos propostos pelo acordo, o argumento é o

6. Sobre o modelo de justiça restaurativa e as suas diferenças à punitiva-retributiva, ver Slakmon, De Vitto e Gomes Pinto (2005). 
de que as suas lideranças políticas não podem participar das eleições e assumir cadeiras no congresso nacional como deputados e senadores enquanto suas sentenças ainda estão em aberto e todas as reparações as vítimas não foram recolhidas, o que potencialmente coloca em risco o sistema político do país. Apesar dos protestos do partido CD, nas eleiçôes de 2018 as FARC elegeram 5 deputados para a Cámara de Representantes ${ }^{7}$ e 5 senadores para o Senado (¿QUÉ INTEGRANTES DE..., 2018, s/p). Por fim, em relação ao narcotráfico, o acordo vigente resolve que este pode vir a ser entendido como delito político conexo a guerra civil e, nestes termos, ser anistiado. Para Duque e o CD, entretanto, o tráfico de drogas não pode ser sujeito a anistia e os membros da FARC devem ser julgados a tal como previsto na constituição colombiana (INTERNATIONAL CRISIS GROUP, 2018).

O sucesso das negociações e o abandono da luta por meio das armas por parte das FARC-EP, em parte se relaciona à promessa de anistia aos crimes políticos cometidos durante os anos de conflito e a abertura à participação política por parte das FARC. Dessa maneira, as mudanças propostas por Duque podem vir a desestabilizar o processo de paz, contribuindo para possível ressurgimento do conflito (GARCÍA, 2016), caso o novo presidente e o CD tenham a capacidade de modificar o acordo por meio de Assembleia Constituinte, referendo derrogatório ou processo legislativo, mesmo que não se descarte como igualmente relevante o curso de ação resposta escolhido pelas lideranças das FARC em caso positivo.

Em relação a Assembleia Constituinte e ao Referendo Derrogatório, como mecanismos mais radicais, seu sucesso significaria de fato rechaçar o acordo, como dito por Fernando Lodońo. Du-

7. Byron Yepes, Jairo Quintero, Jesús Santrich, Marco Calarcá e Olmedo Ruíz.

8. Iván Márquez, Pablo Catatumbo, Victoria Sandino, Carlos Lozada e Sandra Ramírez. que, entretanto, ao longo do pleito eleitoral, afirmou que não pretende convocar constituinte e não deu indícios de que vai seguir o curso do referendo derrogatório (IVÁN DUQUE NO..., 2018). De qualquer maneira, deve ser destacado o movimento de recolha de assinaturas impulsionado por Paloma Valencia, Paola Holguín e Álvaro Hernán Prada, todos parlamentares do CD, em outubro de 2017, para dar legitimidade à proposta de referendar atos legislativos fast track aprovados recentemente pelo Congresso relacionados ao acordo de paz (CENTRO DEMOCRÁTICO RECIBE..., 2017, s/p).

Enfim, no que concerne aos processos legislativos, Duque terá maioria no Congresso, o que potencialmente o coloca em posiçẫo favorável para aprovar resoluçóes ao encontro do proposto pelo Centro Democrático. No entanto, os efeitos destas aos termos de la Habana são incertos, na medida em que atos importantes como os relacionados a JEP e a participação política das FARC já foram aprovados de maneira fast track; além disso pois, em relação ao narcotráfico como "delito conexo", o princípio do in dubio pró réu (princípio de favorabilidad de la ley penal) presente no direito penal colombiano ${ }^{10}$ pode garantir anistia às lideranças do grupo guerrilheiro mesmo se o julgamento de casos dessa natureza se der pela justiça comum, e não pela JEP (INTERNATIONAL CRISIS GROUP, 2018).

\section{Considerações finais}

O eixo delineador deste texto conjuntural foi o de explorar as possíveis consequências da eleiçáo de Iván Duque para o andamento do processo de paz entre a Colômbia e as FARC. Partiu-se do pressuposto de que as mudanças propostas pelo novo

9. Sáo eles relativos aos termos da JEP e da participação política das FARC e a blindagem do acordo de la Habana até 2026.

10. O princípio do in dubio pró réu nos diz que em caso de conflito entre normas com sançóes diferenciadas sobre uma mesma questáo, deve-se ser aplicada àquela menos rigorosa. 
presidente podem comprometê-lo na medida em que contrapóem pontos fundamentais do cálculo estratégico das FARC na decisão de renunciar ao conflito armado. A janela para alterações aos termos de la Habana, no entanto, principalmente após a ratificaçáo de variados atos fast track relativos a temas sensíveis ao acordo vem se fechando para o $\mathrm{CD}$, mesmo após a eleição de Iván Duque.

Ainda que tenha maioria no congresso, por meio de processo legislativo será difícil levar a frente as transformações propostas. Da mesma maneira, a escolha pelo referendo derrogatório ou convocação de constituinte é arriscada em meio a um país substancialmente divido, como aponta o resultado das eleiçóes, pelo qual Duque foi vitorioso com apenas $54 \%$ dos votos válidos. Há que se levar em conta também a possível escolha de curso de ação por parte das FARC em caso de sucesso político de Duque. Apesar de as mudanças propostas não irem de encontro com a posição do grupo desde o início das negociaçôes, o que se evidencia, por exemplo, na retomada das conversas após o resultado do referendo, de fato a última década marcou enfraquecimento material paulatino do grupo guerrilheiro, assim como do suporte da sociedade civil à luta armada, sucessos que podem influenciar a tomada de decisão por parte de suas lideranças.

\section{Referênciass}

ATEHORTÚA, Juan Manuel. “¿Ésta es la paz de Santos?”: el partido Centro Democrático y su construcción de significados alrededor de las negociaciones de paz. Revista CS, n.19, 2016, pp. 15-37.

AZCARATE, Camilo. Psychosocial Dynamics of the Armed Conflict in Colombia. Journal of Peace and Conflict Resolution, v. 2, n. 1, 1999.

BERCOVITCH, Jacob; SIMPSON, Leah. International Mediation and the Question of Failed Peace Agreements: Improving Conflict Management and Implementation. Peace \& Change, v. 35, n. 1, jan. 2010, pp. 68-103.
CENTRO DEMOCRÁTICO RECIBE aval para referendo derrogatório de la JEP. RCN Notícias. 2017. Disponível em: $<$ https://www.noticiasrcn.com/nacional-pais/centro-democratico-recibe-aval-referendo-derogatorio-jep $>$. Acesso em 29 junho de 2018

COLÔMBIA. Acuerdo Final para la Terminación del Conflicto y la Construcción de uma Paz Estable y Duradera. 24 nov. 2016, Bogotá. Disponível em: < http://www.altocomisionadoparalapaz.gov.co/procesos-y-conversaciones/Documentos\%20compartidos/24-11-2016NuevoAcuerdoFinal.pdf $>$. Acesso em: 10 maio 2018.

COLOMBO, Sylvia. Farc retêm sigla e viram partido político colombiano. Folha, Buenos Aires, 02 set. 2018. Disponível em: < https://www1.folha.uol.com.br/mundo/2017/09/1915247-farc-retem-sigla-e-viram-partido-politico-colombiano.shtml>. Acesso em: 06 jun. 2018.

CRONOLOGÍA DE LAS negociaciones entre el gobierno colombiano y las FARC. BBC, 23 set. 2015. Disponível em: < http://www.bbc.com/mundo/noticias/2015/09/150923_cronologia_farc_colombia_paz>. Acesso em: 05 jul. 2018.

FELTER, Claire; RENWICK, Danielle. Colombia's Civil Conflict. Council on Foreign Relations, 11 jan. 2017. Disponível em: <https://www.cfr.org/backgrounder/colombias-civil-conflict>. Acesso em: 28 jun. 2018.

FERNANDO LODOÑO: HAY que "hacer trizas ese maldito papel” de acuerdo con las FARC-EP. Tele Sur. 2017. Disponível em: <https://www.telesurtv.net/news/Fernando-Londono-llama-a-acabar-maldito-acuerdo-con-FARC-EP-20170507-0016.html>. Acesso em 03 de julho de 2018

FORTNA, Virginia P. Scraps of Paper? Agreements and the Durability of Peace. International Organization, v. 57, Spring 2003, pp. 337-372.

GALLEGO, Carlos M. FARC-EP Y ELN: Una historia política comparada (1958-2006). 1057f. Tese (Doutorado) - Programa de Pós-Graduação em História, Universidad Nacional de Colombia, Bogotá, 2010.

GARCÍA, Gloria María. La refrendación e implementación del Acuerdo de Paz no da más espera. Nuevo Foro Penal, v.12, n.87, 2016, pp. 7-15.

GÓMEZ, Gabriel. Entre el castigo y la reconciliación: Análisis socio-jurídico del proceso de paz y la negociación del Acuerdo sobre las víctimas del Conflicto. Estudios Políticos, n.50, 2017, pp. 236-256.

INTERNATIONAL CRISIS GROUP. Risky Business: The Duque Government's Approach to Peace in Colombia. Latin America Report, n.67, p.1-27, 2018. Disponível em < https:// www.crisisgroup.org/latin-america-caribbean/andes/colombia/67-risky-business-duque-governments-approach-peace-colombia>. Acesso em 29 jun. 2018

KROC INSTITUTE. Segundo Informe sobre el Estado Efectivo de Implementación del Acuerdo de Paz em Colom- 
bia: diciembre 2016 - mayo 2018. Instituto Kroc de Estudios Internacionales de Paz, Escuela Keough de Asuntos Globales, Universidad de Notre, Notre Dame, 09 ago. 2017. Disponível em: < https://kroc.nd.edu/assets/284864/informe_2_instituto_kroc_final_with_logos.pdf>. Acesso em: 15 ago. 2018.

LOSADA, Rodrigo; LIENDO, Nicolás. El partido "Centro Democrático" en Colombia: razones de su surgimiento y éxito. Análisis Político, n.87, p.41-59, 2016.

MANDETTO, Francesco. Iván Duque: "no hay que hacer trizas los acuerdos con las FARC, pero sí modificaciones importantes". El País. 2018. Disponível em: <https://elpais.com/ internacional/2018/01/17/colombia/1516162343_892303. html>. Acesso em 03 de julho de 2018.

MARTUSCELLI, Patricia N.; VILLA, Rafael D. Child soldiers as peace-builders in Colombian peace talks between the government and the FARC-EP. Conflict, Security \& Development, v. 18, n. 5, 2018, pp. 387-408.

MELO, Jorge O. Resumen del acuerdo de paz. Revista de Economía Institucional, v. 18, n. 35, 2016, pp. 319-337. Disponível em: <http://www.scielo.org.co/pdf/rei/v18n35/ v18n35a18.pdf>. Acesso em: 28 jun. 2018.

OBSERVADORES DA ONU concluem processo de remoção de armas na Colômbia. Naçóes Unidas, 17 ago. 2017. Disponível em: <https://nacoesunidas.org/observadores-da-onu-concluem-processo-de-remocao-de-armas-na-colombia/>. Acesso em: 30 jun. 2018.

¿QUÉ INTEGRANTES DE Farc irán al congreso colombiano. TelesurTV. 2018. Disponível em: < https://www.telesurtv. net/news/nuevos-actores-politicos-farc-congreso-colombiano-20180312-0009.html>. Acesso em 19 out. 2018

RESTREPO, Jorge; SPAGAT, Michael; VARGAS, Juan F. The Dynamics of Colombian Civil Conflict: A New Data Set. Homo Oeconomicus, v. 21, n. 2, pp. 396-428, 2004.

SLAKMON, Chatherine; DE VITTO, Renato; GOMES PINTO, Renato. Justiça Restaurativa. Brasília: Ministério da Justiça e PNUD, 2005

STEDMAN, Stephen J. Spoiler Problems in Peace Processes. International Security, v. 22, n. 2, Fall 1997, pp. 5-53.

VILLEGAS, Luiz Carlos A. Pacto y renuncia: la experiencia del Frente Nacional, un esfuerzo de los partidos políticos tradicionales en Colombia para asegurarse el poder del Estado. In: $9^{\circ}$ Congresso da Associaçáo Latino-americana de Ciência Política; 24-28 jul. 2017; Montevidéu. Montevidéu: ALACIP; pp. 1-21, 2017.

WALLENSTEEN, Peter. Understanding Conflict Resolution: War, Peace and the Global

System. London: Sage Publications, 2007.

WALLENSTEEN, Peter; ERIKSSON, Mikael. Negotiating Peace Lessons from Three Comprehensive Peace Agreements. Uppsala: Universitetstryckeriet, 2009. Disponível em: $<$ https://peacemaker.un.org/sites/peacemaker.un.org/files/Ne-
gotiating\%20PeaceLessonsfrom3Agreements_WallensteenEriksson2009.pdf>. Acesso em: 15 jun. 2018.

ZARAMA, Felipe. Caguan's and Havana's Peace Talks: Strategic Retreat or Stalemate Driven? In: CANTE, Fredy; QUEHL, Hartmut. Handbook of Research on Transitional Justice and Peace Building in Turbulent Regions. Hershey: Information Science Reference, 2016. 